\title{
A Numerical Simulation of LNG Low Temperature Pipe Pre-Cooling Process
}

\author{
Hong-Zhi ZHANG ${ }^{1}$, Jun-Man SHU ${ }^{1}$, Li-Ping DONG ${ }^{1}$, Guo-Rui ZHANG ${ }^{2}$, \\ Xuan-Yu SHENG ${ }^{3}$, ${ }^{*}$, Ling CHEN $^{4}$ \\ ${ }^{1}$ Daqing OilField Construction Group Co., Ltd. Installment Co.Beijing, China \\ ${ }^{2}$ Dalian University of Technology \\ ${ }^{3}$ Department of Mechanical Engineering, Tsinghua University, Beijing, China \\ ${ }^{4}$ Tianjin Research Institute for Advanced Equipment, Tsinghua University, Tianjin, China \\ ${ }^{a}$ xuanyu@tsinghua.edu.cn \\ *Corresponding author
}

Keywords: LNG Low Temperature Pipe, Pre-cooling, Numerical Simulation.

\begin{abstract}
LNG Low Temperature pipe pre-cooling is difficult point of completion and commissioning of LNG project, under the flow rate of $0.2 \mathrm{~m} / \mathrm{s}, 0.5 \mathrm{~m} / \mathrm{s}$ and $1 \mathrm{~m} / \mathrm{s}$, FLUENT software is used to conduct simulation of BOG gas pre-cooling technology for $63010 \mathrm{~mm}$ Low Temperature pipe to obtain temperature change regularity of pipe during BOG pre-cooling process and real-time display of temperature of Low Temperature pipe during pre-cooling process and to formulate precooling plan of Low Temperature pipe.
\end{abstract}

\section{Preface}

After the constructions of LNG cryogenic pipelines are finished, the LNG pipelines should be processed by precooling. Because LNG is a liquefied natural gas (LNG), the operating temperature is -163 degrees. Direct input without precooling will not only cause shrinkage deformation, but also cause bending deformation and thermal stress damage, which is due to the top and bottom surface temperature difference of the low temperature pipes because cooling is too fast .

Precooling is the key work to ensure that the LNG project could be put into trial operation successfully. First of all, the cold BOG gas circulate in the pipeline, cooling must be carried out slowly, the pipeline temperature reach to 95 -118, then LNG can be directly delivered. Through the precooling, LNG pipeline temperature drops from room temperature to low degree of working state, which ensures the operation of LNG cryogenic pipelines.

\section{Low Temperature Pipeline Structure}

Take the domestic LNG pipeline as an example, diameter of cut off part for horizontal straight pipe is $63010 \mathrm{~mm}$ and its length is $5 \mathrm{~m}$, this cut off part is the object of study. Pipeline structures are simplified to consist of the steel pipe and cold insulation layer, the BOG are selected as precooling gas, $20 \mathrm{~mm}$ thick $0 \mathrm{Cr} 18 \mathrm{Ni} 9$ are selected as steel pipe, and insulation layer of pipeline is composed of two layers, inner layer is composed of polyisocyanurate foam, which is $100 \mathrm{~mm}$ thick, outer layer is composed of foam glass, which is $50 \mathrm{~mm}$ thick, physical parameters are listed in Table 1.

Tab.1 Physical parameters of pipeline structure

\begin{tabular}{ccccc}
\hline Parameters & $\begin{array}{c}\text { Density } \\
\left(\mathrm{kg} / \mathrm{m}^{3}\right)\end{array}$ & $\begin{array}{c}\text { Specific } \\
\text { heat }(\mathrm{kJ} / \mathrm{kgK})\end{array}$ & $\begin{array}{c}\text { Kinematic } \\
\text { viscosity } \\
\left(\mathrm{m}^{2} / \mathrm{s}\right)\end{array}$ & $\begin{array}{c}\text { Thermal } \\
\text { conductivity } \\
\mathrm{W} /(\mathrm{mK})\end{array}$ \\
\hline $\begin{array}{c}\text { BOG } \\
\text { 0Cr18Ni9 }\end{array}$ & 0.717 & 2223 & $1.43710^{-5}$ & 0.03 \\
Polyisocyan & 7860 & 460 & $/$ & 11.8 \\
u-rate Foam & 80 & 358.7 & $/$ & 0.019 \\
Foam glass & 16 & 880 & $/$ & 0.06 \\
\hline
\end{tabular}




\section{Model Building}

When the BOG gas are injected into pipe, through heat transfer with the pipe wall surface, the BOG gas temperature increases, so the pipeline precooling could be realized. When pipeline is precooled to a certain temperature, cold amount is transferred to the inner insulation layer. Since then, through heat conduction between internal and external insulation layer and heat convection transfer of external insulation layer and the atmosphere environment, the external insulation layer temperature of pipeline gradually reduced. The actual precooling process of the low temperature pipe is more complex. Therefore, for the convenience of the study, the model needs to be simplified:

(1) Neglecting the axial heat conduction of the pipe wall, only considering the radial heat conduction;

(2) Neglecting the thermal contact resistance between the outer wall of the pipe and the cooling layer;

(3)Thermal conductivity and other physical properties of heat pipe wall and cold insulation materials will not change with temperature.

On the basis of the above simplified assumptions, the model satisfies the continuity equations, momentum equations and energy equations, the formulations are shown in equation $(1) \sim(5)$, and the heat conduction differential equation of the insulation layer is shown in equation (6):

$$
\begin{aligned}
& \frac{\partial \rho}{\partial \tau}+\nabla \cdot(\rho \vec{U})=0 \\
& \frac{\partial(\rho u)}{\partial \tau}+\operatorname{div}(\rho u \vec{U})=\operatorname{div}(\mu g r a d u)+S_{u}-\frac{\partial p}{\partial x} \\
& \frac{\partial(\rho v)}{\partial \tau}+\operatorname{div}(\rho v \vec{U})=\operatorname{div}(\mu g r a d v)+S_{v}-\frac{\partial p}{\partial y} \\
& \frac{\partial(\rho \omega)}{\partial \tau}+\operatorname{div}(\rho \omega \vec{U})=\operatorname{div}(\mu g r a d \omega)+S_{w}-\frac{\partial p}{\partial z} \\
& \frac{\partial\left(\rho c_{p} T\right)}{\partial \tau}+\operatorname{div}\left(\rho c_{p} \vec{U} T\right)=\operatorname{div}(\lambda g r a d T)+S_{T}
\end{aligned}
$$

The heat conduction differential equation satisfying the insulation layer is:

$$
\frac{\partial(\rho h)}{\partial \tau}+\nabla(\rho h)=\nabla\left(K_{e f f} \nabla T\right)+S_{h}
$$

\section{Numerical Simulation Results and Analysis}

Inject the $153 \mathrm{~K}$ BOG gas into pipeline which is 5 meters long at flow rate of $0.2 \mathrm{~m} / \mathrm{s}$, precooling the pipeline. Time step is set to $60 \mathrm{~s}$, save a set of data every 10 minutes, the total calculation time is $12 \mathrm{~h}$, at initial time pipeline and ambient temperature is set to $303 \mathrm{k}$. Fig. 1 shows contours of temperature when pipe is precooled for $10 \mathrm{~min}$. 


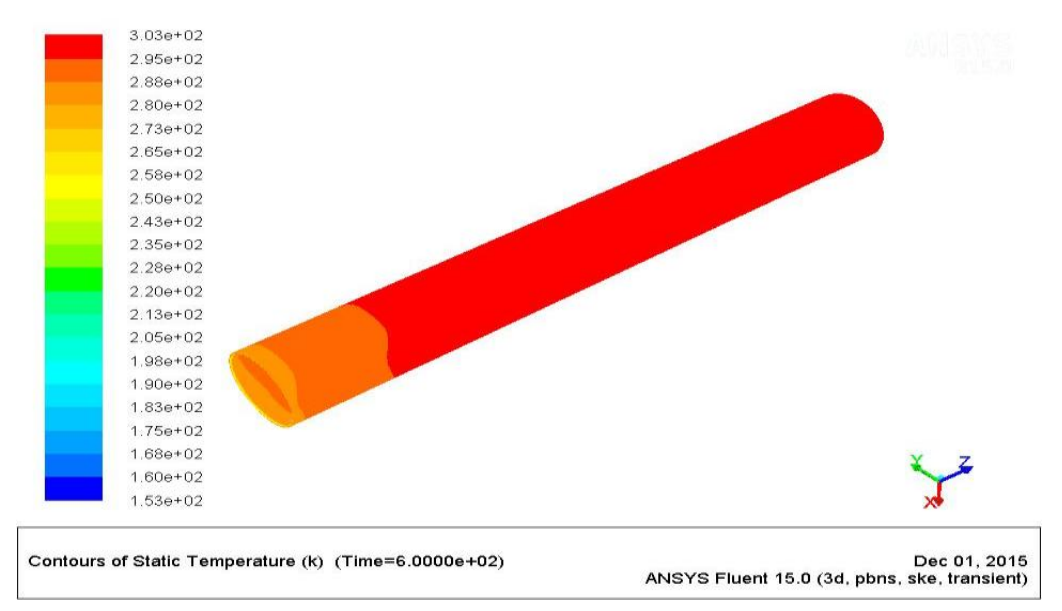

Fig.1 Temperature distribution of BOG pipeline for10min precooling

When the BOG gas flow into the pipe at $0.2 \mathrm{~m} / \mathrm{s}, 0.5 \mathrm{~m} / \mathrm{s}$ and $1 \mathrm{~m} / \mathrm{s}$ respectively, the temperature drop of these three conditions for $12 \mathrm{~h}$ precooling is simulated, and the temperature drop curve of the pipeline wall is obtained, as shown in Fig.2.

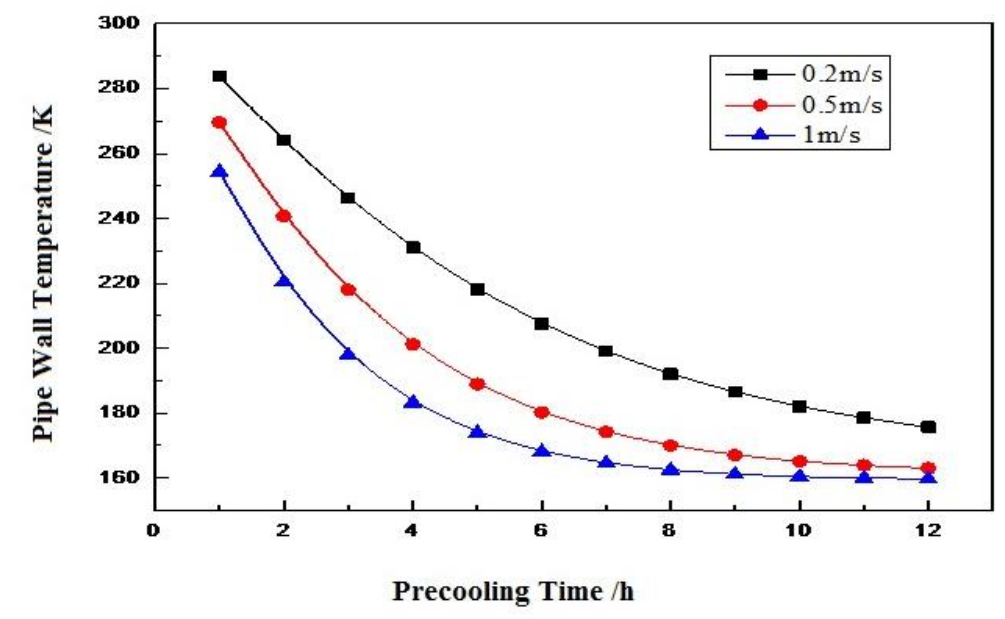

Fig.2 Curve of pipe wall temperature along with precooling time at different flow velocities

As can be seen from Fig. 2, the overall trend of three different flow rates of BOG pipeline precooling all change rapidly at first and then tends to be flat and has largest velocity of temperature drop within 1 hour precooling, temperature drop curve changes faster within the first 10 hours when the velocity is $0.2 \mathrm{~m} / \mathrm{s}, 10$ hours later the temperature drop curve will change slowly; temperature drop curve changes faster within the first 7 hours when the velocity is $0.5 \mathrm{~m} / \mathrm{s}$, then the change tends to be slow; the temperature drop curve changes faster in the first 5 hours when the velocity is $1 \mathrm{~m} / \mathrm{s}$, then the change tends to be slow. Mainly because of the low BOG temperature of inlet pipe section, the pipeline temperature differences are large, the convective thermal transfer coefficient is large, so the pipeline temperature drops faster. Therefore, it is necessary first to precooling at minimized velocity and increase velocity slowly.

Because in pipe precooling process, the pipe wall temperature decreased gradually, and reaches a certain temperature, the cooling capacity are transfer to pipe inner insulation layer, internal insulation layers temperature is transferred to the outer thermal insulation layer through thermal conduction, this is also because convective thermal transfer between external thermal insulation layer and the atmosphere environment, so the thermal insulation layer temperature will have minor decreasing amplitude, Fig. 3 shows contours of cross-section temperatures under different flow rates for $12 \mathrm{~h}$ precooling. 


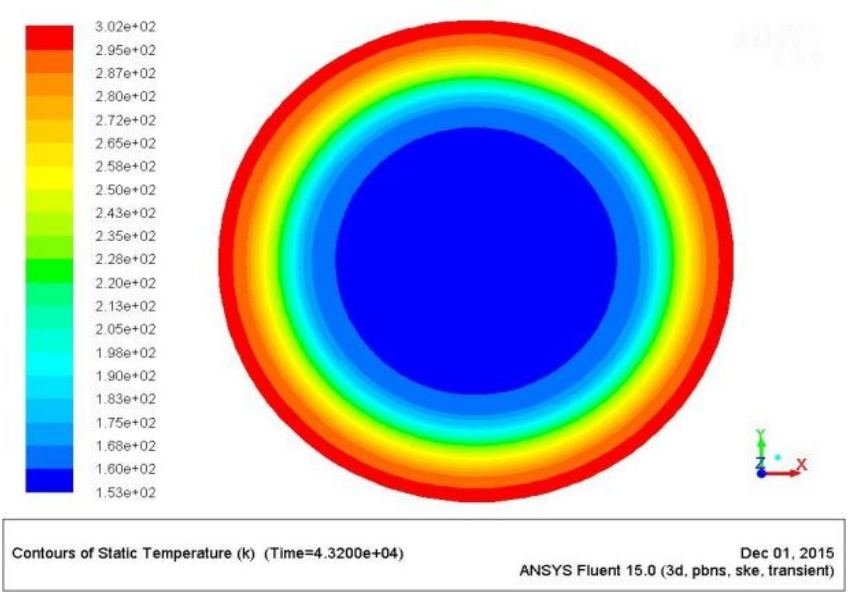

(a) is at flow rate of $0.2 \mathrm{~m} / \mathrm{s}$

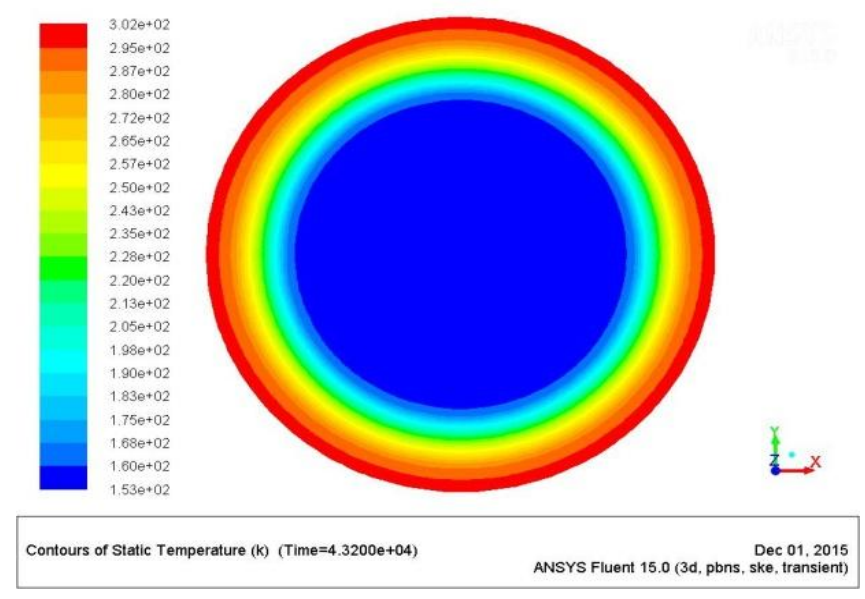

(b) is at flow rate of $0.5 \mathrm{~m} / \mathrm{s}$

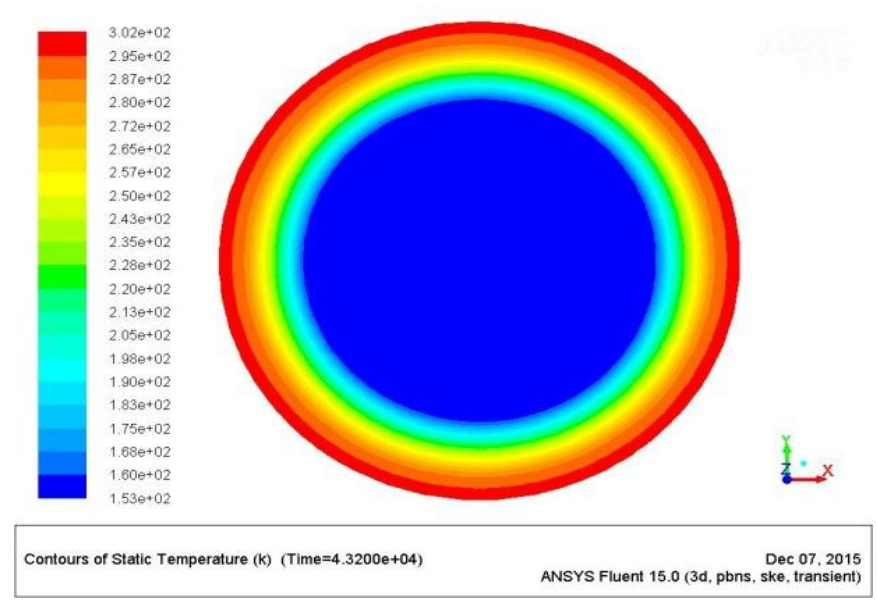

(c) is at flow rate of $1 \mathrm{~m} / \mathrm{s}$

Fig.3 the cross-section temperatures under different flow rates for $12 \mathrm{~h}$ precooling.

\section{Conclusions}

This paper use FLUENT software to simulate LNG pipeline precooling, calculate and analyze the pipe flow and pipeline temperature distribution of pipe, which is $610 \mathrm{~mm}$ in diameter and 5 meters long, in precooling process. This paper then compares and analyzes the internal pipe wall temperature variation under different flow rates within $12 \mathrm{~h}$ of precooling, calculate low temperature pipelines thermal stress and contraction displacement according to the temperature results data. Results show that the temperature drop curves of $0.2 \mathrm{~m} / \mathrm{s}, 0.5 \mathrm{~m} / \mathrm{s}$ and $1 \mathrm{~m} / \mathrm{s}$ change faster at time of 
$10 \mathrm{~h}, 7 \mathrm{~h}$ and $5 \mathrm{~h}$ respectively, which provide the references for the precooling of LNG low temperature pipeline.

\section{References}

[1] ChaoLu, Rui Duan, BOG gas precooling process of LNG gas pipeline numerical simulation, The 3rd China LNG Forum.

[2] Junwei Yan, Zhaoci Li. LNG cryogenic pipe precooling process numerical simulation, Cryogenics and Superconductivity, No. 9.

[3] Hongmei Yu, Zhaoci Li. Study on the precooling process of horizontal pipeline, Pipeline Technology and Equipment, 2009, No. 6. 